\title{
Aproximaciones al itinerario narrativo de José Martí
}

\section{Approaches to the Narrative Itinerary of José Martí}

\section{Aproximações ao itinerário narrativo de José Martí}

\author{
Mauricio Núñez-Rodríguez \\ Doctor en Ciencias Literarias \\ Investigador Titular \\ Centro de Estudios Martianos \\ Cuba \\ Recibido: 4/08/2018 \\ Aceptado: 10/11/2018 \\ DOI:https: //doi.org/10.15359/tdna.35-65.5
}

\section{Resumen}

Este ensayo constituye un acercamiento a la faceta de narrador de José Martí la cual ha quedado en la periferia de interés de la crítica ante la obra poética, periodística y revolucionaria del autor. Es una indagación que se detiene en un grupo de piezas que constituyen un sistema narrativo en su obra literaria que no se atiene a los cánones tradicionales.

Palabras clave: José Martí, sistema narrativo, crónica, periodismo, literatura latinoamericana

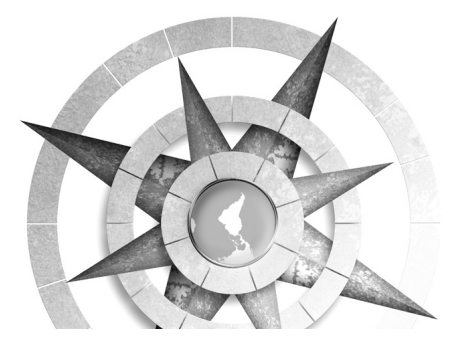

Keywords: José Martí, narrative system, chronicle, journalism, Latin American Literature.

\section{Resumo}

Este ensaio é uma abordagem à faceta de José Martí como narrador. Esta faceta ficou na periferia do interesse do crítico pela obra poética, jornalística e revolucionária do autor. Trata-se de uma investigação que se detém num conjunto de peças que constituem um sistema narrativo na sua obra literária que não respeita os cânones tradicionais. 
Palavras chave: José Martí, sistema narrativo, crônica, jornalismo, literatura latino-americana

En concordancia con las tesis del teórico israelí Itamar Even-Zohar, puede establecerse un sistema narrativo en la creación literaria de José Martí que no se ha justipreciado en la misma dimensión que otras facetas de su quehacer, pero que muestra sus primeras expresiones en algunos de sus textos juveniles escritos durante su estancia en España: Castillo y El presidio político en Cuba (1871), el cuento Hora de lluvia (1873), las dos versiones del drama Adúltera (1872-1874) y concluye en sus Diarios de campaña (1895).

El sistema narrativo martiano -cuya naturaleza no se atiene siempre a los géneros tradicionales o canónicos- constituye parte indisoluble de su poética, tanto desde el punto de vista estilístico como conceptual, y sus peculiaridades se van complejizando paralelamente a su madurez intelectual.

Las piezas más distintivas de este sistema narrativo emergen en la etapa de mayor estabilidad y creación literarias del poeta durante los años que vive en los Estados Unidos, aproximadamente entre 1880 y 1895. A este periodo corresponde el cuento Irma (1884), se conoce Amistad funesta (1885), sus traducciones de novelas (Misterio, 1886 y Ramona, 1888); la traducción del cuento Mes fils de
Víctor Hugo se publica en 1875 en la Revista Universal de México.

Integran, además, su sistema narrativo los relatos de los cuatro números de la revista La Edad de Oro (1889), y su labor como cronista. A esta colección habría que agregar sus diarios de viaje por México, Guatemala y Venezuela, y los fragmentos de novelas y cuentos de los Cuadernos de apuntes así como la naturaleza narrativa de su poesía. El Cuento de la guerra. El teniente Crespo publicado en el periódico Patria en $1892^{1}$ también articula este sistema.

En un trazado exhaustivo del itinerario narrativo del autor habría que tener en cuenta los relatos y fragmentos pertenecientes a diferentes etapas de su vida -en los que casi nunca se reparadispersos en sus Cuadernos de apuntes recopilados por Ángel Esteban en el volumen José Martí: Cuentos completos. La Edad de Oro y otros relatos.

1 José Martí: "Cuento de la guerra. El teniente Crespo", en Obras completas, t. 4, edit. Ciencias Sociales, 1991, pp. 365-370 (Esta pieza brinda las hazañas combativas de Jesús Crespo, un soldado del ejército independentista cubano. El autor le imprime el mismo ritmo del combate: el movimiento incesante de los jinetes, de los machetes, de los rifles, los disparos que van y vienen. Es una narración en pleno campo de batalla que se caracteriza por oraciones breves, sustantivos adjetivados con precisión y objetividad, se evita la subordinación y el encadenamiento sintáctico. La expresión es fluida, clara y directa sin digresiones en la acción).
72 Aproximaciones al itinerario narrativo de José Martí Mauricio Núñez-Rodríguez 
En cuanto a los relatos y fragmentos de los Cuadernos de apuntes hemos encontrado diecisiete, casi todos de pocas líneas. En el cuaderno no. 2, de la época española (1871-1874), hay ocho fábulas de necios, muy cortas, con cierto contenido moral o didáctico. [...] en el cuaderno no. 9, de 1882, hemos encontrado dos fábulas [...]. Por último, en el cuaderno no. 18 , de 1884 , se encuentra el relato más original -fuera de los de La Edad de Oro, mejor elaborado y de mayor fuerza expresiva de Martí, que hemos titulado "Cuchillo de plata fina" y otro más, titulado "El drama" (Esteban, 1995: XLI)

Pero esta es una investigación por hacer. Al definir los antecedentes narrativos en la obra del autor debemos tener en cuenta, sobre todo, a sus textos juveniles, a aquellos que pertenecen a su etapa española. El cuento Hora de lluvia se puede ubicar en esta consideración. La nota que lo antecede está fechada el 29 de abril de 1873 y se dirige a Blanca de Montalvo, la novia de Martí en Zaragoza. Se publicó sin firma en el no. 17 de la Revista Universal de México, en octubre de 1875.

El texto constituye un autorretrato de su estado anímico en ese momento. En el diálogo entre los dos personajes emergen sus angustias, sus ansias, sus deseos. "La patria me ha robado para sí mi juventud" (Martí, 1981: p. 8) afirma el narrador, seguramente al referirse a la etapa en que estuvo en presidio y a las huellas físicas y síquicas resultantes.

La narración está dividida en siete secciones. Es una pieza que, supuestamente, se escribe en una hora y su discurso está glosado por un elemento temporal y, a la vez, estructurador: "a las ocho y media", "son las nueve", "son las nueve y diez", "son las nueve y veinticinco minutos". El argumento del cuento es continuidad de su constante preocupación por la entrega a la patria. Es un motivo que se reitera. Una idea expresada en otras piezas correspondientes a esta etapa.

Es frecuente afirmar que Amistad funesta o Lucía Jerez es la única pieza escrita por José Martí en el género novelístico. Su versión al idioma español de la novela Ramona de Helen Hunt Jackson -a pesar del conocido estilo de José Martí al realizar esta faena- la considero una traducción. Según la crítica, Martí acostumbraba a enriquecer el discurso con su acervo personal; pero, en este caso, el autor se apoya en un texto de partida que constituye el volumen de la escritora norteamericana-. Véase El traductor Martí, de Lourdes Arencibia (2000) o el trabajo de diploma: Ramona: un nuevo movimiento de ficción prolongada (2001) de Maia Barreda Sánchez.

Es cierto que existen múltiples afinidades entre el traductor y la obra seleccionad, de ahí que se genere una estrecha 
empatía. Ninguna otra novela deja en él tan alta impresión. En esta ocasión se establece una identificación plena entre José Martí y la obra, la autora, los personajes, el asunto recreado, las situaciones dramáticas y el espacio donde se desarrolla la acción: Baja California, un territorio de México (país latinoamericano muy caro al autor).

Los elogios martianos a esta novela son bien elocuentes. Es de las piezas con las que establece un diálogo mantenido desde su labor creativa: "esta novela, verdaderamente notable", "Helen Hunt Jackson, [...], ha escrito quizás en Ramona nuestra novela", "esa novela encantadora de la vida californiana", "salud y piedad infunden en el espíritu aquellas páginas artísticas y ardientes”. Cuando Martí refiere nuestra novela expresa un sentido de pertenencia como crítico, traductor y también como latinoamericano. Ante ninguna otra pieza de las reseñadas en sus crónicas mostró tanta complicidad.

José Martí traduce Ramona en momentos en que ya la pieza tenía una trayectoria en los Estados Unidos en su lengua original. Primero apareció de forma seriada en el semanario The Outlook en 1884 y, después, en forma de libro en 1885. Decide presentar al lector hispanoamericano un texto exitoso. La primera edición de su traducción es de 1888. Así, lo considero un traductor con un peculiar estilo porque existe un texto de partida con una trayectoria previa. Más su traducción de Ramona se conoce en el año 1888, es decir, posterior a la escritura y publicación de Amistad funesta (1885). Creo más atinado considerar esta traducción más como parte de su itinerario narrativo posterior a su novela que como parte de sus antecedentes narrativos.

La actividad traductora de José Martí subyace en gran parte de su obra literaria, tanto en prosa como en verso (Suárez, 2002) y forma parte de su gran afán por mantener informado a los pueblos hispanoamericanos del acontecer, no solo cultural, sino también político, económico, científico y tecnológico de los Estados Unidos.

Según la Cronología del Dr. Ibrahim Hidalgo Paz (2012), Martí concluye el "Prólogo" para la edición -que ya estaba en imprenta- en septiembre de 1887. Posiblemente su labor de traducción corresponde al primer semestre, es decir, siempre posterior a la redacción y publicación de su novela. La impresión de Ramona concluye en julio de 1888.

La creación dramática de José Martí también le sirvió de referente en el momento de la escritura de su única novela. El drama también descansa en un conflicto, el cual debe tener una introducción, un desarrollo y unas conclusiones de manera evolutiva y gradual, dividido en actos y estos, a
74 Aproximaciones al itinerario narrativo de José Martí Mauricio Núñez-Rodríguez

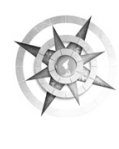


su vez, en escenas. Seguramente al autor le fue útil su entrenamiento en la construcción de personajes, caracterizarlos psicológicamente y el trazado de las complejidades de cada uno a lo largo de la acción.

Crear situaciones dramáticas creíbles y orgánicas fue la estrategia que le sirvió en los siete apresurados días en que redactó su novela, los personajes y las complejidades de sus caracterizaciones psicológicas.

Si partimos de la condición sine qua non de que para que exista un relato tiene que haber un conflicto y para que exista un drama debe mediar una situación conflictiva, entonces José Martí se nutrió de su experiencia anterior como dramaturgo y de esas estructuras dramáticas. La intriga que se teje a lo largo de la acción en Adúltera ante los ojos del lector, que obliga a preguntarse si uno de los personajes sorprenderá a su esposa con el amante, se reitera años más tarde en su novela, con el destino de los celos descontrolados de la protagonista. Toda su obra dramática es anterior a la escritura de su novela. Cada una de sus piezas pudieran considerarse antecedentes en mayor o menor medida del discurso de esta. Existe en el autor la necesidad de observar y recrear artísticamente las profundas complejidades del alma humana. Su talento creador lo brinda empleando todos los recursos de que dispone.
Las dos versiones de Adúltera corresponden a la estancia del autor en España (1872-1874). Son textos de juventud. Las marcas del discurso erótico que concentra la atención de la crítica sobre su novela en la etapa 2003-2013 pudiera tener su antecedente en los diálogos y parlamentos de Adúltera. Hay similitudes en el final trágico de ambas historias: mientras que en Adúltera el esposo engañado elimina al sujeto de la infidelidad (el amante de su esposa), en la novela, la protagonista decide poner fin -de manera dramática y brutal- a la vida del personaje por el que siente amenazado su amor por Juan Jerez. Asimismo, la sensualidad que caracteriza el discurso de Amor con amor se paga (México, 1876) aparece nuevamente en Lucía Jerez. Incluso, desde una pieza tan temprana como Abdala (1869), el autor dibuja una psicología femenina en conflicto. Más allá de la firme decisión del protagonista de cumplir los deberes con la patria ¿Qué mayor dilema para una madre que ver partir a uno de sus hijos para una guerra?

Hay zonas de su obra dramática que convergen en el discurso de la novela. En un estudio ya publicado, (Núñez, 2003) establezco los vasos comunicantes que se establecen entre Patria y libertad (Drama indio), escrito durante su estancia en Guatemala, el ensayo Guatemala y el discurso de su novela. La obra dramática del autor, como corpus -en su condición 
narrativo-dialógica- puede integrar los antecedentes, no solo narrativos, en su creación en relación con la novela.

En el año 2000 en el taller Lucía Jerez: desafí al tiempo -a propósito de los 115 años de publicada la obra- Cintio Vitier y Fina García Marruz brindaron las intervenciones iniciales. García Marruz expresó que entre las múltiples lecturas que le inspiraba la pieza-además de lo ya expresado en su estudio publicado en varias ocasiones- estaba la de imaginarla como una representación teatral, pues cada una de las escenas estaban dibujadas como si fueran a ser entregadas a un director para su puesta en escena. Esa lectura, decía, le inquietaba desde hacía muchos años y como resultado de ello había escrito, décadas atrás, un guión para ballet, pero que por timidez nunca mostró a ningún especialista y mucho menos al Ballet Nacional. A través de gestiones de la institución, el texto llegó a manos de Alicia Alonso. Posteriormente se conoció el ballet a partir de la idea de García Marruz.

$\mathrm{Y}$ es cierto, hay numerosas escenas en el discurso de Lucía Jerez que parecen haber sido elaboradas para ser representadas: el concierto del pianista Keleffy, por ejemplo, o la interpretación de Sol del Valle, ambas en el tercer capítulo. Pero hay dos escenas plenamente dramáticas: el monólogo interior de Lucía Jerez en su cuarto, que permite conocer el alcance de la fiereza de su carácter y que es el preludio de la escena final donde expresa el desenfreno de sus celos cuando toma una de las pistolas de adorno en la hacienda campestre y le dispara a Sol del Valle.

A diferencia de otras novelas en que la protagonista muere, sufre o le pide a otro personaje que lleve a cabo su venganza, ${ }^{2}$ en esta narración la protagonista es quien ejecuta, con sus propias manos, la trágica decisión de eliminar al personaje que la hace vulnerable. Este inusual final, de cierto modo, la aleja de la sensibilidad del siglo XIX.

Es conocida la intensa y heterogénea creación periodística del poeta en los Estados Unidos en los aproximadamente quince años que vivió allí. Esta labor antecede, acompaña y se mantiene, después de la escritura y publicación de su novela, pero no son textos de juventud, sino que corresponden al periodo de mayor madurez, estabilidad y creación intelectual de José Martí. En el trazado de un itinerario narrativo en su obra literaria -tanto anterior como posterior a Lucía Jerez-, su labor como cronista ocupa un lugar significativo.

2 En la última escena de la novela Cecilia Valdés de Cirilo Villaverde, la protagonista conversa con José Dolores Pimienta y le expresa que el matrimonio entre Leonardo e Isabel no puede consumarse. Este rápidamente se dirige a la Iglesia del Santo Ángel Custodio y, en ese momento, ella le dice: "A él no. A ella”. En la versión cinematográfica de Humberto Solás mientras Pimienta va corriendo por las calles de La Habana Vieja recuerda como un eco las recientes palabras de Cecilia: "A él no. A ella".
76 Aproximaciones al itinerario narrativo de José Martí Mauricio Núñez-Rodríguez 
Numerosas de sus escenas españolas y norteamericanas muestran una simiente narrativa. En la crónica que escribe el 24 de diciembre de 1881 dirigida a La Opinión Nacional titulada "Puertos y porteños” (Martí, 1991: pp. 293-296) comienza presentando al lector la ciudad de Santander de forma integral: su gente, su arquitectura, sus fuentes de empleo, la naturaleza; seguidamente lo hace con Valladolid, antes de concentrarse en los sucesos noticiosos que le interesan de esas regiones. En otra, del 15 de abril de 1882, (Martí, 1991: pp. 473-477) hilvana fluidamente tres núcleos noticiosos de diferente naturaleza: protestas en Barcelona por la firma de un tratado comercial entre Francia y España, la presencia de Sarah Bernhardt en un teatro de Madrid y la muerte del torero Ángel Pastor. Tres acontecimientos incoherentes entre sí como parte de una misma narración sobre la vida española de la época. Su tempo es ágil, sin digresiones ni extensas descripciones ni detalles innecesarios. Resulta una crónica muy bien estructurada con un final conmovedor por la agonía del joven torero después de ser embestido por un toro en la plaza de Madrid.

El volumen sobre las Escenas norteamericanas que preparó el departamento de la edición crítica del Centro de Estudios Martianos para las Ediciones Archivo (Rodríguez y Fernández Retamar, coords., 2003) de Francia, coordinado por los doctores Roberto Fernández Retamar y Pedro Pablo
Rodríguez, publicado en 2003, reúne algo más de trescientas piezas. De la lectura, cotejo y análisis de la información como parte del equipo que lo preparó, surgió posteriormente el ensayo José Martí: narrar desde el periodismo (Núñez, 2014: p. 228). El estudio se detiene en la evolución de la actitud narrativa en dos conjuntos de crónicas martianas de diferente naturaleza: uno de perfil político (las dedicadas al caso Cutting) y aquellos textos desde los cuales el poeta le brinda la bienvenida a tres de las estructuras que simbolizan la modernidad en los Estados Unidos (la crónica sobre la inauguración de la Estatua de la Libertad, las que dedica al Puente de Brooklyn y a la referida a Coney Island).

Cualquiera de estas crónicas pudiera ser leída a partir de su naturaleza narrativa. En una de las que dedica al puente de Brooklyn, (Martí, 2011), por ejemplo, ofrece detalles de cada una de las etapas de su proceso de edificación, de las dimensiones y características de todas sus estructuras metálicas, así como de las múltiples complejidades y tropiezos afrontados por los especialistas y constructores desde las primeras labores, pero se detiene, además, en la biografía de los dos ingenieros (padre e hijo) que lo hicieron posible y del rol desempeñado por la esposa y madre para la culminación de la compleja obra.

Esta cualidad de la crónica es la que permite que más de un estudioso coincida con la idea de trazar una historia 
novelada de los Estados Unidos a través de las Escenas norteamericanas, al menos en la etapa en que su autor permaneció allí. No es casual que el propio autor denomine a sus crónicas escenas en la carta a Gonzalo de Quesada y Aróstegui antes de partir para la guerra de Cuba en 1895 -documento considerado como su testamento literario y donde le concede suma valía a esta sección (Martí, 1991: p. 479).

En el discurso de Lucía Jerez se entrelazan el poeta, el periodista, el crítico, el narrador, el traductor, el dramaturgo y el agudo observador y analista. De ahí la confluencia genérica en sus páginas, que transitan por la narración, el periodismo, el ensayo, el drama, siempre con un profundo lirismo. Numerosos textos martianos no pueden analizarse según los géneros canónicos o tradicionales, sino que la simbiosis discursiva es lo que predomina. En el caso de su novela, son múltiples las voces que confluyen en su discurso: es un texto singular.

El texto de la novela martiana dialoga con la propia creación anterior del autor $y$, a su vez, no solo con el legado de otros artífices que le anteceden, sino también con los que le son contemporáneos. La presencia de las novelas María (1867), del colombiano Jorge Isaacs, y Amalia (1851), del argentino José Mármol, cons- tituyen la continuidad de esa comunicación ahora desde el propio texto.

No es casual que dos personajes estén disfrutando de su lectura como expresión de las preferencias de ese momento: "Pedro, de otras mujeres tan temido, era con la mayor tranquilidad puesto por Sol, ya a que le leyese la Amalia de Mármol o la María de Jorge Isaacs". (Martí, tomo 18: p. 262)

Siempre me he preguntado si la presencia de ambos títulos sería, además, un indicio -que de manera subliminalpresagia el trágico final de la pieza, a partir del desenlace desafortunado de aquellas historias, si tenemos en cuenta el estilo en que han sido presentado los rasgos de los caracteres de cada personaje a través de la imagen de las tazas que usan o de las flores que prefieren. Ese detalle se suma a la intención marcada del narrador de sugerir más que decir. Pero su presencia confirma, no solo el conocimiento del autor en torno a la creación novelística de la época, sino también su preferencia por estas piezas románticas y sus autores mostrada en otras ocasiones en su quehacer.

La historia de amor entre Efraín y María solo vuelve a ser aludida desde $\mathrm{La}$ Nación a propósito de una versión al inglés: "Boston lee mucho español y aplaude en la versión inglesa la María,

3 Ver José Martí: OCEC, t. 22, pp. 300-301. 
de Isaacs" (OC, t. 6, p. 78). Todo parece indicar que el interés por Amalia era superior. En 1887 desde las páginas de El Partido Liberal a propósito de una referencia a su autor decía: "Mármol, el de la épica Amalia"(p. 352) y la atención continuaría en un futuro, si nos guiamos por su colección de Fragmentos: "Las mujeres rusas recuerdan la Amalia de Mármol: ¿cómo?-porque, seres humanos los de acá y los de allá, viven bajo la misma tiranía: Rusia; Rosas" (OC. t. 22, p. 65). A la muerte del autor argentino parece ser que Martí tuvo pensado preparar alguna semblanza al estilo de las que dedicó a personalidades (y otros personajes) desde sus Escenas norteamericanas. Uno de sus múltiples fragmentos así lo confirma:

Oh! Indudablemente: con Mármol se fue de la tierra algo del corazón americano.-Con cada gran poeta se va de la tierra algo del propio corazón.

-iQué asunto de amor, de dolor, de patria no ha movido las cuerdas de su lira?, ¿ni qué pincel copió con más delicadeza el espíritu a la par tierno y enérgico, alma de águilas en cuerpo de gacelas, de los gentiles bonaerenses? Su novela Amalia tiene todo el sombrío color de su época. La escribió un gran poeta con la pluma de un gran historiador. (p. 165)
La trágica historia de amor entre Amalia Sáenz y Eduardo Belgrano se enmarca durante la etapa de Juan Manuel de Rosas en Argentina (1832-1852), específicamente en la etapa comprendida entre el 4 de mayo y el 5 de octubre de 1840 , meses en los que se realiza una enconada persecución contra sus opositores (los unitarios). Este año ha trascendido en la historia como el año del terror.

El diálogo de José Martí con esta pieza de José Mármol y con la creación novelística romántica posiblemente continuaría -de no haber ocurrido aquel fatídico 19 de mayo- no solo como narrador y periodista sino también como crítico. Así lo demuestran otros apuntes de sus Fragmentos donde menciona una breve relación de novelas que posiblemente estudiaría o al menos le interesaban:

La novela en América

Manuela

Enriquillo

María Julia?

Amalia

Martín Rivas

La Novia del Hereje

Los Amores de Marta

¿Brenda (?)

La de Milla.

Francisco,-Cecilia Valdés.

de Meza-El Capitán L. de la Cruz. (pp. 227-228) 
Si bien estos personajes estaban disfrutando de la lectura de dos de las creaciones que fueron legitimadas posteriormente como las más representativas del romanticismo en América Latina -lo que denota la fina sensibilidad del autor y su agudeza crítica- esa presencia en el fragmento citado forma parte del interés del narrador en mostrar lo más reciente, lo más novedoso de la sociedad en torno a la creación artística, musical y literaria de la época, rasgo propio de la narrativa modernista.

Romanticismo y modernismo no son estéticas contrapuestas. El segundo es el resultado de la adaptación del primero a los nuevos tiempos. Son los cambios que impone la complejidad de una sociedad más moderna. El discurso de la novela posee rasgos que la relacionan con la etapa romántica y, a su vez, otros la vinculan con la nueva época que se estaba gestando en las letras del continente en esos años y de la que el autor fue un precursor.

El conflicto principal de la pieza -en primera instancia- es la trágica historia de amor entre dos personajes: Juan Jerez y su prima Lucía Jerez. Felicidad que se ve truncada por la llegada a escena de un tercero: Sol del Valle. La acción, a su vez, está ambientada en un aparente paradisiaco país; el excesivo deleite por las ruinas de ciudades antiguas en el capítulo III; el contraste entre los personajes (la enfermedad de Ana y la vitalidad de Adela, la cándida Sol ante la complejidad de Lucía o la frivolidad de Pedro Real ante el profundo compromiso social de Juan Jerez): todos son rasgos genuinamente románticos.

Si por una parte, el cambio de título que pensó Martí para su novela podía estar relacionado con maneras de proceder típicas de la literatura latinoamericana del momento, otras marcas de su discurso, sin embargo, la distancian de ella. Su condición de poeta raigal genera que el discurso de la novela sea una prosa de alta calidad poética evidente, tanto en el lenguaje de los personajes como desde la voz del narrador. Es notable su interés en resaltar la belleza, no solo en la caracterización de los personajes, sino también de los entornos donde se desarrolla la acción dramática, tanto de los espacios interiores como de los naturales. Ese es un rasgo que caracteriza la narrativa modernista

La minuciosa descripción del vestuario de los personajes femeninos, sus sombreros y las particularidades de sus tazas de chocolate afines a cada temperamento constituyen expresión de elegancia y gusto refinado, y están muy relacionados con la moda en los Estados Unidos en ese momento. Si se comparan las muestras del Suplemento de modas que acompañaba cada edición del periódico El Latino-Americano, con las descripciones del narrador se hallarán similitudes. Las modas recientes que
80 Aproximaciones al itinerario narrativo de José Martí Mauricio Núñez-Rodríguez

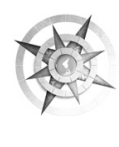


rodeaban al autor en las calles, quizás pudieron ser fuente para la minuciosa descripción del narrador.

Asimismo sucede con la caracterización de los espacios. La casa donde sucede la acción dramática no es una casa común. Cada objeto que se describe como parte de la decoración es singular, exquisito: los libros de la repisa son piezas esenciales de la literatura universal (El Cuervo, de Edgar Allan Poe; Las Noches de Alfredo Musset; o el Rubayat, el poema persa), los cuadros de la sala son de notables pintores (Madrazo, Nittis, Fortuny), el patio de la casa está lleno de magnolias que se caracterizan por el color blanco de sus pétalos, unos personajes hablan de las modas de París y de Bélgica, otros asisten a la versión operística de Rigoletto. Existe un interés marcado por mostrar el gusto por la novedad y un ambiente de modernización cultural, social y política de un entorno, lo que es propio de la narrativa modernista. El diálogo que establece el discurso de la novela con la pintura, la escultura, la música y la literatura, lo enaltece. No es casual que varios de los personajes sean creadores: una pintora (Ana), un músico exitoso (Keleffy) y un poeta (Juan Jerez); a partir de su caracterización y de sus diálogos llegan a la narración los asuntos sobre el arte. Incluso, en varias ocasiones, el narrador reflexiona sobre las funciones del arte:
Mejora y alivia el contacto constante de lo bello. Todo en la tierra, en estos tiempos negros, tiende a rebajar el alma, todo, libros y cuadros, negocios y afectos, jaún en nuestros países azules! Conviene tener siempre delante de los ojos, alrededor, ornando las paredes, animando los rincones donde se refugia la sombra, objetos bellos, que la coloreen y la disipen. (OCEC, t. 22, 2011, p. 245).

El discurso de la novela se apropia de los instrumentos expresivos que brindan estas artes, característica que distingue a la narrativa modernista. Todo ello aparece imbricado en el texto presagiando sutilmente el destino de los personajes. La presencia del pianista Keleffy crea correspondencias entre su música y la pintura. Con sus notas al piano: "en las nubes de colores ligeros iban dibujándose unas como guirnaldas de flores silvestres" (p. 270) o a través de las imágenes que se esbozan en los lienzos de Ana se expresan los conflictos dramáticos. En la novela se establece un diálogo de símbolos entrecruzados por la correspondencia entre diversas expresiones artísticas. Una arista que es evidente también en el discurso de las crónicas martianas. Otra deuda del periodismo, específicamente de la crónica modernista.

También, en el sistema de personajes, el protagonista masculino no es un simple galán de amores. Es un poeta,

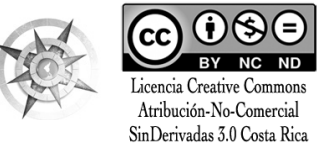


es un intelectual que tiene un proyecto social definido en función de la defensa de los derechos a la tierra de los pobladores originarios. Su caracterización es singular: "Era de la raza selecta de los que no trabajan para el éxito, sino contra él”. Es el héroe ético de la novela por su integridad, por su conducta, por su personalidad. La crítica lo ha definido como un intelectual moderno con un proyecto anticolonial.

El horizonte de expectativas en torno a la única novela de José Martí ha experimentado cambios sustanciales desde 1953 hasta los estudios aparecidos en el año 2013. Después de varias décadas de silencio, el ensayista argentino Enrique Anderson Imbert presenta su estudio en el Congreso de Escritores Martianos -efectuado en febrero de 1953 en La Habana, a propósito del centenario del natalicio de José Martí.

La ensayista cubana Margarita Mateo Palmer (2015: p. 159) afirma que:

Un primer acercamiento a la novela martiana, debido a las características románticas del asunto recreado por Martí y a la presencia de algunas expresiones típicas de la sensibilidad del siglo XIX, distancian la novela martiana de la sensibilidad actual y parecen situarla en un campo similar al de las novelas leídas en el propio texto. Sin embargo, una lectura más atenta a las claves narrativas ofrecidas por la obra, permite ubicarla en los inicios de ese cambio de signo hacia una nueva narrativa que alcanzará una fuerza extraordinaria en el siglo XX, y también, en un plano más renovador que las novelas que son lectura predilecta de los propios personajes creados por Martí.

El grado de experimentación y libertad expresiva que le permitía a José Martí la crónica como género se deslizó en el momento de la escritura de su novela y, quizás, ello pudiera explicar la naturaleza heterogénea del discurso de cada uno de sus capítulos o lo entrecortado del propio discurso novelístico que alterna la narración con largas secciones reflexivas del narrador sobre asuntos que le preocupan del contexto, similares a los abordados en sus crónicas periodísticas, pero que interfieren la fluidez del relato. La novela es un espacio de confluencia genérica. Eso la convierte en un texto atípico para su tiempo y, quizás, una de las razones que, al parecer, continúa desarticulando a los lectores. Su naturaleza por momentos se acerca no solo al ensayo, sino también al drama; a ratos, a la crónica; o, de repente, el propio narrador cita la opinión de un cronista, publicada ese día en un diario.

A su vez, desde la voz de los personajes, el diálogo está permeado por el estilo noticioso al comentar estos sucesos o
82 Aproximaciones al itinerario narrativo de José Martí Mauricio Núñez-Rodríguez

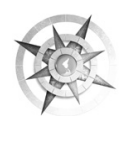


desde la voz regente en el discurso se transparenta el tono periodístico, quizás para brindar elementos contextuales al lector. Véase Amistad funesta: diálogo intertextual, de Marlene Vázquez Pérez (2000) donde se abordan estas correspondencias con mayor profundidad.

Las irregularidades de su discurso (es decir, esos tres capítulos conformados de diferente forma y de naturaleza discursiva dispar, con cierta fragmentación interna y una fluidez de la acción dramática que no es homogénea) quizás también responden a esa fragmentación peculiar de la crónica modernista apuntada por Susana Rotker (1991) y que será algo propio de la novela que surge posteriormente en el continente. Es una novela del siglo XIX con un discurso y estructura inquietantes para la crítica de cada periodo desde su publicación con el nombre del autor.

\section{Referencias bibliográficas}

Arencibia, L. (2000). El traductor Martí. Pinar del Río: Ediciones Hermanos Loynaz.

Centro de Estudios Martianos. Obras Completas Edición Crítica. La Habana.

Centro de Estudios Martianos. Obras Completas. La Habana.
Esteban. A. (1995). "Prólogo”, en José Martí: Cuentos completos: La Edad de Oro y otros relatos. Barcelona : Instituto de Cultura "Juan Gil-Albert" y Anthropos.

Hidalgo Paz, I. (2012). José Martí. Cronología (1853-1895). La Habana: Centro de Estudios Martianos.

Martí, J. (1991). "Puertos y porteños", en Obras completas, t. 14, edit. Ciencias Sociales, pp. 293-296. (1991). "Cataluña contra España”, en Obras completas, t. 14, edit. Ciencias Sociales, 1991, pp. 473-477

Martí, J. (1981). Hora de lluvia. Anuario del Centro de Estudios Martianos, no. 4, La Habana, p. 8

Mateo Palmer, M. (2015). "De una novela sin arte: Lucía Jerez y la narrativa moderna en Hispanoamérica”, en Anuario del Centro de Estudios Martianos, no. 38, La Habana.

Nuñez, M. . (2003). El espacio americano en la novela de José Martí, en Anuario del Centro de Estudios Martianos, no. 25. La Habana:, pp. 168-176.

. (2014). Martí. Narrar desde el periodismo. Colección Patria. La Habana: Editorial Martí.

Rotker, S. (1991). Fundación de una escritura: las crónicas de José Martí. La Habana: Casa de las Américas. 
Suárez León, C. (2002). "Martí: tra- Vázquez Pérez, M. (2000). "Amistad ductor de textos, traductor de mundos", en Anuario del Centro de Estudios Martianos, no. 25, La Habana, p. 178 funesta: diálogo intextextual" en Anuario del Centro de Estudios Martianos, no. 23. La Habana: Centro de Estudios Martianos, pp. $46-53$ 